\title{
Epistemologia de "nosotras": mulheres do campo, das águas e das florestas
}

\author{
Graziela Rinaldi da Rosa ${ }^{1}$, Cheron Zanini Moretti ${ }^{2}$ \\ ${ }^{1}$ Universidade Federal de Rio Grande - FURG. Instituto de Educação-Campus São Lourenço do Sul. Mal Floriano Peixoto, \\ 2236, Centro. São Lourenço do Sul - RS. Brasil. ${ }^{2}$ Universidade de Santa Cruz do Sul - UNISC. \\ Autor para correspondência/Author for correspondence: grazirinaldi@gmail.com
}

A Revista Brasileira de Educação do Campo (RBEC), ISSN 2525-4863, periódico do Departamento de Educação do Campo, da Universidade Federal do Tocantins, campus de Tocantinópolis, lança o seu quarto número do volume 3, referente ao terceiro quadrimestre de 2018. Este número traz 13 artigos, aprovados dentre os manuscritos recebidos ao longo de 2018, conforme chamada pública para esse dossiê.

O mesmo foi idealizado na ocasião do III Seminário das Mulheres do Campo, das Águas e das Florestas (2017) que tem acontecido anualmente na Universidade Federal do Rio Grande/FURG coordenado pela professora Graziela Rinaldi da Rosa e realizado em parceria com diversos grupos, coletivos, instituições e mulheres de movimentos sociais, como, por exemplo, as mulheres líderes dos quilombos, mulheres do MST, do Movimento de Consciência Negra, entre outras. Os seminários têm contado especialmente com o protagonismo de lideranças do Coletivo Feminista Dandaras/FURG. Durante os seminários estabelecemos diálogos com uma significativa diversidade de mulheres de povos tradicionais, como, por exemplo, quilombolas, indígenas, pomeranas, agricultoras familiares, ciganas, mulheres da cadeia produtiva da pesca, benzedeiras, mulheres de povos de terreiro, entre outras.

Assim, com a inserção da professora Graziela Rinaldi em estágio de PósDoutoramento, sob supervisão de Cheron Zanini Moretti, pensamos ser relevante reunir trabalhos científicos que expressassem as diferentes experiências educativas dessas mulheres e seu vínculo com teorias do conhecimento. Além disso, no âmbito do Grupo de Pesquisa: Educação Popular, Metodologias Participativas e Estudos Decoloniais, na Universidade de Santa Cruz do Sul (UNISC), a caminhada de pesquisa apontava para a necessidade de relacionar Educação do Campo, mulheres e epistemologias.

Assim, entendemos que existem "formas de fazer e de pensar" o conhecimento a partir da realidade das mulheres do campo, das águas e das florestas. E, passamos a denominar de "epistemologia de nosotras" àquelas produzidas pelas e para as mulheres, em sua maioria, relacionadas à perspectiva feminista; mas também, a busca de diálogos com as experiências, os saberes e os fazeres produzidos pelas mulheres, em especial, em território latinoamericano. Assim, quando publicizamos a chamada para o recebimento de manuscritos para a composição desse dossiê, a fizemos com a evidente intenção de "convocar" os/as

\begin{tabular}{|l|l|l|l|l|l|l|l|} 
Rev. Bras. Educ. Camp. & Tocantinópolis & v. 3 & n. 4 & p. i-v & set./dez. & 2018 & ISSN: 2525-4863 \\
\hline
\end{tabular}


pesquisadores/as à reflexão sobre a experiência comum das mulheres que a escrevem a sua agência histórica desde as margens.

Organizamos o sumário desse dossiê partindo das discussões sobre epistemologia, seguindo para aquelas que relacionam o campo da educação popular com o feminismo; em seguida, um grupo de artigos sobre mulheres em seus povos tradicionais para, então, seguir com trajetórias de vida, experiências de escritas e concluir com processos de formação das mulheres na educação do campo. Esperamos que essa ordenação faça sentido quando de sua leitura atenta e crítica.

Conforme mencionamos, o primeiro conjunto de artigos corresponde à discussão epistemológica. O dossiê é inaugurado pelo artigo intitulado Descautivar o pensamento pedagógico latino-americano: (des) colonização e (des) patriarcalização a partir da crítica feminista de autoria de Cheron Zanini Moretti, da Universidade de Santa Cruz do Sul (UNISC) e de Graziela Rinaldi da Rosa, da Universidade Federal de Rio Grande (FURG), bolsista PNPD/Capes na Universidade de Santa Cruz do Sul (UNISC). Nesse artigo, as autoras apresentam e desenvolvem as ideias de descautivar, descolonizar e despatriarcalizar a pedagogia a partir de teóricas feministas latino-americanas tomando-as como "fontes", as quais nos ajudam a (re)criar bases epistemológicas de "nosotras" ante as epistemologias dominantes. As aproximações e diálogos entre várias feministas levaram à compreensão de "sororidade" e de "ética feminista" como parte imprescindível de um pacto de complexas relações no fortalecimento experiências comuns das mulheres, em especial, quanto ao saber/conhecer, poder e ser. Nesse movimento, além dos caminhos para descautivar, descolonizar e despatriarcalizar essas relações, concluem que há outros para (re)existir e resistir na consubstancialidade entre raça, classe e gênero.

Em seguida, de autoria de Lia Pinheiro Barbosa, da Universidade Estadual do Ceará (UECE), encontra-se o artigo intitulado Epistemologias de Nosotras, Feminismos e Teoria da Selva na construção do conhecimento: aportes das mulheres Zapatistas. Captando o chamado público para esse dossiê, a autoria apresenta alguns elementos do que considera ser epistemologia de nosotras, articulando-a a concepção de luta das mulheres erigida pelas indígenas Zapatistas, em Chiapas, México. A partir da experiência zapatista, destaca elementos teórico-epistêmicos e políticos que articulam o que denomina feminismo insurgente, revolucionário, rebelde e autônomo dessas mulheres indígenas camponesas.

No que podemos considerar "segundo grupo de artigos", encontramos Feminismo camponês e popular: uma história de construções coletivas, de Michela Calaça, da Universidade Federal Rural do semiárido (UFERSA) e doutoranda da Universidade Federal de Campina Grande (UFCG), de Isaura Isabel Conte e de Catiane Cinelli, ambas da Universidade Federal de Rondônia (UNIR). Nesse artigo, as autoras descrevem e analisam o processo de construção do Feminismo Camponês e Popular no Movimento de Mulheres Camponesas (MMC), destacando o fato de que o feminismo camponês e popular ser um fenômeno recente, fruto da identidade coletiva das mulheres do referido movimento. Além disso, a partir de metodologias participativas, observam que a sua construção acontece na articulação com outras organizações camponesas de mulheres e feministas tendo como base o trabalho, a defesa da agroecologia e a libertação.

Em seguida, tomamos contato com o trabalho desenvolvido por Carla Negretto e Márcia Alves da Silva, pesquisadoras na Universidade Federal de Pelotas (UFPel) sob o título: Problematizando o trabalho invisível das mulheres e a divisão sexual de trabalho no campo: uma parceria entre educação popular e feminismo. Nesse artigo, as autoras desenvolvem algumas reflexões sobre a experiência de pesquisa com mulheres assentadas da Reforma Agrária, desde 2014, no interior do município de Pinheiro Machado/RS. Para tanto, exploraram o espaço social e as experiências de vida, dando vozes às mulheres na relação 
com o seu trabalho, debatendo juntamente com os homens aspectos da reprodução social que divide atribuições, tarefas e lugares entre os gêneros. Articulam educação popular e feminismo para problematizar a invisibilidade e a divisão sexual do trabalho.

Em Mulheres, Trabalhos e Histórias: uma análise das trajetórias de vida em uma Comunidade Teuto-Brasileira do RS, Tatiana Souza de Camargo e Muriel Closs Boeff, da Universidade Federal do Rio Grande do Sul (UFRGS) apresentam as intersecções entre duas pesquisas realizadas em um mesmo município de colonização alemã, localizado na Encosta da Serra Gaúcha. Dessa forma, puderam compreender as contribuições das trajetórias de vida para a organização da comunidade, principalmente em termos de alternativas de trabalho e estratégias educativas em Educação do Campo, para a sucessão geracional da agricultura familiar no município e, em especial, a incorporação da temática de gênero para a qualidade de vida desta população. Esse é, portanto, o artigo que inaugura uma sequência de outros que têm como foco a trajetória de mulheres camponesas.

Deiviani de Oliveira, Luan Eudair Bridi, Miriã Lúcia Luiz, Regina Godinho de Alcântara, da Universidade Federal do Espírito Santo (UFES) buscam compreender a trajetória de mulheres camponesas no Espírito Santo de um longo período (de 1930 a 2017). Para tanto, analisam os discursos e as narrativas de quatro camponesas capixabas disponíveis nos Cadernos da Realidade dos estudantes da Licenciatura em Educação do Campo/UFES. Destacam a mulher ocupando os espaços domésticos, o modelo patriarcal de família e de sociedade. Como descontinuidades nessas trajetórias, evidenciam: a inserção no processo de escolarização, o protagonismo no âmbito doméstico, comunitário e nos espaços mais amplos da sociedade, como a Universidade. $\mathrm{O}$ artigo está intitulado: Trajetórias de mulheres camponesas no Espírito Santo: permanências e descontinuidades.

Na relação das mulheres com os povos tradicionais, temos a contribuição de autoria de Cleide Carvalho de Matos e Manuelle Espíndola dos Reis, da Universidade Federal do Pará (UFPA). Sob o título de Educação de mulheres ribeirinhas no município de breves, o artigo analisa a abordagem de gênero que permeia a proposta curricular do ensino fundamental das escolas do campo do município de Breves, tomando em conta os conhecimentos sobre a mulher ribeirinha incluídos no documento. As autoras concluem que a proposta curricular das escolas do campo apresenta uma discussão frágil sobre gênero, pautada em uma concepção biológica que, de um modo geral, silencia as mulheres. Ainda, no documento analisado, observam que não se identifica referência alguma à mulher ribeirinha, suas histórias de luta e resistência.

No artigo Experiências educativas e empoderamento das mulheres indígenas Kaingang: formação de professoras/es em educação do/no campo, Moises Marques Prsybyciem e Almir Paulo dos Santos, da Universidade Federal da Fronteira Sul (UFFS)- Campus Erechim, Rejane Fernandes da Silva Vier e Rosemari Monteiro Castilho Foggiatto Silveira, da Universidade Tecnológica Federal do Paraná (UTFPR), Campus Ponta Grossa, apresentam como objetivo compreender o contexto das mulheres indígenas Kaingang no Curso Interdisciplinar em Educação do Campo: Ciências da Natureza - Licenciatura da Universidade Federal da Fronteira Sul (UFFS), Campus Erechim, discutindo aspectos como as experiências educativas da participação feminina na construção do conhecimento científico e o empoderamento da mulher indígena com sua inserção na educação superior. De acordo com as suas análises, essas mulheres possuem uma elevada representatividade no curso de Licenciatura em Educação do Campo e que a sua presença na educação superior contribui para a construção da autonomia, para o empoderamento e a resistência dos povos indígenas. Além disso, apontam a importância da participação das mulheres kaingangs na construção do conhecimento científico e sua ressignificação, levando em consideração as dinâmicas sociais e culturais dos povos do/no campo.

\begin{tabular}{|l|l|l|l|l|l|l|l|}
\hline Rev. Bras. Educ. Camp. & Tocantinópolis & v. 3 & n. 4 & p. i-v & set./dez. & 2018 & ISSN: 2525-4863 \\
\hline
\end{tabular} 
$\mathrm{Na}$ sequência, damos a conhecer o artigo intitulado A escrita de educandas do campo sobre sentidos da prática pedagógica em escolas do campo. A partir dele, reunimos alguns artigos que têm como foco a escrita. Assim, Elisvânia Nunes Braz, do Instituto Federal do Pará (IFPA) e Nilsa Brito Ribeiro da Universidade Federal do Sul e Sudeste do Pará (UNIFESSPA) buscar apreender as diferentes vozes que permeiam as representações das mulheres sobre o fazer pedagógico em escolas do campo. Como resultados analíticos, identificaram nos relatórios de estágios das educandas, a presença de discursos sobre o "como fazer" pedagógico; e para a relação conflituosa entre os saberes escolarizados e os saberes do cotidiano dos sujeitos da aprendizagem. Concluem, ainda que provisoriamente, que os discursos dos sujeitos apresentam desafios e potencialidades abertos à multiplicidade de vozes.

Sônia Maria Alves de Oliveira Reis, da Universidade do Estado da Bahia (UNEB) e Carmem Lúcia Eiterer, da Universidade Federal de Minas Gerais (UFMG) em Práticas de leitura e escrita de mulheres camponesas: reflexões a partir de algumas histórias de apropriação, apresentam práticas de leitura e escrita de mulheres camponesas com pouca escolarização. Para tanto, utilizaram-se da história oral, de diário de campo constituído a partir dos eventos de letramento observados nas CEBs e de entrevistas, com a finalidade de identificar formas de acesso e apropriação de materiais escritos pelas mulheres. Assim, puderam apreender os significados, os papéis e as concepções que as líderes das CEBs atribuem à leitura e à escrita, especificamente a partir de algumas histórias de apropriação. As autoras também puderam interpretar que as diferentes formas de participação nas culturas do escrito dessas mulheres se pautam na mediação entre o oral e o escrito.

Também tomando como foco trajetórias e histórias de vida, Rony Rei do Nascimento Silva, da Universidade Estadual Paulista (UNESP) e Ilka Miglio de Mesquita, da Universidade Tiradentes (UNIT) buscaram compreender o trabalho, a escola e a trajetória no magistério com aposentadas. Analisaram narrativas de dezesseis professoras e considerara que, apesar das condições de precariedade de instalações e da formação de seus professores, as mulheres tiveram importante papel na institucionalização do ensino primário em Sergipe. O artigo está intitulado Mulheres com enxadas e lápis na mão: histórias de professoras primárias no meio rural sergipano (1930 - 1950) correspondendo a um contexto histórico brasileiro específico de crescente urbanização.

Por fim, apresentamos o último "bloco" de artigos. Os mesmos correspondem ao "subtema" que é o da formação de educadoras. Em Perspectivas e análises do processo formativo de educadoras no projeto tecendo a cidadania no campo, Alisson Silva da Costa, Cláudia Valéria de Assis Dansa e Nathália Barros Ramos, da Universidade de Brasília (UnB) analisam o trabalho pedagógico de educadoras participantes do Programa Nacional de Educação na Reforma Agrária (PRONERA). A partir dos limites e desafios apontados pelas educadoras no projeto "tecendo a cidadania no campo", identificaram a dificuldade em atualizar a prática docente ao público da EJA; a falta de aproximação com uma abordagem de educação libertadora; a escassez de material didático e dificuldade com a escrita e leitura por parte das educadoras. Como achados, destacaram algumas motivações e expectativas em relação ao projeto, tais como: o prazer de ensinar e poder participar de momentos de troca de experiências; a consciência e o dever de ajudar o próximo; a necessidade de alfabetização dentro do assentamento; a busca por melhorias na realidade; entre outros.

No artigo intitulado Teorías feministas en el aula: una experiencia de formación e investigación con estudiantes de Ciencias de la Educación de Weimar Giovanni Iño Daza, da Universidad Mayor de San Andrés (La Paz, Bolivia) podemos conhecer através da descrição e apresentação, uma experiência de formação e de pesquisa em teorias feministas da universidade do autor. A partir das disciplinas de Sociologia Geral e Sociologia da Educação no curso de Ciências da Educação percebe-se a relação entre as teorias feministas com a

\begin{tabular}{|l|l|l|l|l|l|l|l|}
\hline Rev. Bras. Educ. Camp. & Tocantinópolis & v. 3 & n. 4 & p. i-v & set./dez. & 2018 & ISSN: 2525-4863 \\
\hline
\end{tabular}


educação, cuja ênfase se encontra no feminismo ecológico e no feminismo comunitário. Os principais resultados apontam que as aulas podem gerar espaços de discussão e diálogo, de modo que a educação formal a partir de uma pedagogia comunitária feminista pode ser transformador, além de desconstruir o sistema patriarcal e neocolonial. $\mathrm{O}$ autor considera, ainda, que as aulas desenvolvidas nas referidas disciplinas se constituem em espaços de concientização, de empoderamento e ruptura dos círculos de opressão e de saber patriarcal.

Dessa forma, podemos retomar as ideias do artigo que abre esse Dossiê, vinculando teoria e prática descolonial e despatriarcal na construção de uma epistemología de nosotras, uma vez que a epistemología dominante invisibiliza e/ou nega a (re)existência e a resistência de outras formas de saber, poder e ser. Quais as contribuições de uma epistemologia própria para a vida em comum? Essa e outras questões se abriram na leitura desses 13 artigos.

Como organizadoras desse Dossiê temático, agradecemos a cada um dos/das autores/as pela submissão de seu manuscrito ao periódico e, igualmente o nosso agradecimento, ao conjunto de avaliadores/as ad hoc que contribuíram para a qualificação dessa edição ao emitirem os seus pareceres.

Agradecemos, de modo muito especial, aos editores da Revista Brasileira da Educação do Campo pela possibilidade de colocarmos em discussão as epistemologias produzidas por mulheres no contexto da educação e dos povos do campo, das águas e das florestas.

Desde o sul do Brasil, desejamos uma boa leitura.

Graziela Rinaldi da Rosa e Cheron Zanini Moretti.

Informações do Editorial / Editorial Information

Conflitos de interesse: As organizadoras deste Dossiê declararam não haver nenhum conflito de interesse referente a este Editorial e a este número publicado.

Conflict of Interest: None reported.

Orcid

Graziela Rinaldi da Rosa

iD https://orcid.org/0000-0002-0347-2949

Cheron Zanini Moretti

(iD) https://orcid.org/0000-0002-6297-3129

Como citar este Editorial / How to cite this Editorial

APA

Rosa, G. R., \& Moretti, C. Z. (2018). Epistemologias de "nosotras": mulheres do campo, das águas e das florestas. Rev. Bras. Educ. Camp., 3(4), i-v. DOI: http://dx.doi.org/10.20873/uft.2525-4863.2018v3n4pi

ABNT

ROSA, G. R.; MORETTI, C. Z. Epistemologias de "nosotras": mulheres do campo, das águas e das florestas. Rev. Bras. Educ. Camp., Tocantinópolis, v. 3, n. 4, set./dez., p. i-v, 2018. DOI: http://dx.doi.org/10.20873/uft.2525-4863.2018v3n4pi

\begin{tabular}{|l|l|l|l|l|l|l|l|}
\hline Rev. Bras. Educ. Camp. & Tocantinópolis & v. 3 & n. 4 & p. i-v & set./dez. & 2018 & ISSN: 2525-4863 \\
\hline
\end{tabular}

